\title{
CORRECTION
}

\section{Correction to: Anaerobic Degradation of Chloroanilines by Geobacter sp. KT5}

\author{
Ha Danh Duc ${ }^{1} \cdot$ Nguyen Thi Oanh ${ }^{2}$
}

Published online: 22 March 2019

(c) Springer Science+Business Media, LLC, part of Springer Nature 2019

\section{Correction to: Current Microbiology \\ https://doi.org/10.1007/s00284-018-1617-7}

The original version of this article unfortunately contained a mistake. The authors would like to correct the heading "Anaerobic Biodegradation Intermediates, Enzyme Activities, and the Biodegradation Pathways for CAs" in the Results section. The correct heading should read as "Anaerobic Biodegradation Intermediates and the Biodegradation Pathways for CAs".

Publisher's Note Springer Nature remains neutral with regard to jurisdictional claims in published maps and institutional affiliations.

The original article can be found online at https://doi.org/10.1007/ s00284-018-1617-7.

Ha Danh Duc

hadanhduc@gmail.com

1 Faculty of Engineering-Technology, Dong Thap University, Pham Huu Lau St., Cao Lanh, Dong Thap, Vietnam

2 Center for Chemical Analysis, Dong Thap University, Pham Huu Lau St., Cao Lanh, Dong Thap, Vietnam 